\title{
Investigating the oxidation behavior of carbon steel in fire scene: a new method for fire investigations
}

\author{
Hao Hong ${ }^{\mathrm{a}}$, Dongbai Xie ${ }^{\mathrm{b}}$, Shuwang Duo ${ }^{\mathrm{a}, *}$, Wen Wang ${ }^{\mathrm{c}}$ \\ a Jiangxi Key Laboratory of Materials Surface Engineering, Jiangxi Science and Technology Normal \\ University, Nanchang 330013 China \\ b School of Material Science and Engineering, Nanchang Hangkong University, Nanchang 330063 China \\ c Institute of Metal Research, Chinese Academy of Sciences, Shenyang 110016 China
}

*Corresponding author, e-mail: swduo@imr.ac.cn

Received 25 Jul 2019

Accepted 30 Dec 2019

\begin{abstract}
A major component of fire investigation is tracking the cause of fire, finding of which help to strengthen the physical evidence, especially in case of arson with accelerants. When metallic substances are exposed to fire at high temperature, they undergo oxidation. Accelerants at the fire scene impart some oxidative characteristics on metallic materials. For instance oxides and substrates found on metal surfaces provide valuable information for determining the characteristics of fire, such as exposure temperature, duration and involvement of a liquid accelerant. In this study, we investigated the oxidation behavior of carbon steel at high temperature in a simulated flame environment using ethanol combustion. After oxidation, the morphological and microstructural features of the samples were characterized by observation, scanning probe microscope, X-ray diffractions and scanning electron microscopy with energy-dispersive spectroscopy analysis. The results showed that elemental carbon was deposited on the samples surface, which were ascribed to the incomplete combustion of ethanol. An oxide with a mesh-like pattern appeared on the samples, which was ascribed to the complex oxidation conditions of the fire scene. The properties of the oxides were strongly dependent on the oxidation duration, temperature and atmosphere. These results provide reference information for determining the presence of combustion accelerants at the fire scene.
\end{abstract}

KEYWORDS: fire investigation, arson, carbon steel, ethanol, oxidation

\section{INTRODUCTION}

In legal disputes, high quality evidence based on scientific methods is desirable. In case of firerelated matters, the evidence found at the fire scene must be analyzed correctly and interpreted accurately [1]. In order to accurately identify the origin and cause of the fire, fire investigators need to collect all related traces of evidence and perform comprehensive scientific analysis. However, this is very challenging in some cases due to the complex nature of fire scenes, especially in cases where the physical evidence is easily damaged or difficult to extract. It is difficult to establish the cause of arson since the motivation for arson is often complex. In most instances, arson is started by ignitable liquid accelerants $[2,3]$. One of the major tasks of fire investigators at the crime scene is to collect the fire debris which contains traces of ignitable compounds $[3,4]$. Chemical analysis is one of the most widely used techniques by fire investigators. Some scholars propose that GC-MS can be used to analyze traces of ignitable compounds such as gasoline, medium-petroleum fractions, and heavy petroleum distillates from fire residues $[5,6]$. Recent advances in methods of extracting and analyzing information such as gas chromatography have enabled the determination of biodiesel in fire residues [2]. The American Society for Testing and Materials (ASTM) recommends some methods for fire debris analysis [7-9]. However, the accuracy of these methods in chemical analysis depends on the purity of the samples. In the case of samples obtained from burning scenes, volatile fuels, such as gasoline and ethanol, may be difficult to analyze $[10,11]$. The complex environment at fire scenes produces different oxidation characteristics on metals [12]. In a fire scene, the oxidative products generated by the combustion of liquid accelerants will promote oxidation of metallic substances. This oxidation is affected by type of combustion accelerant and burning duration and other factors such as the thickness, composition, surface pattern and color of 


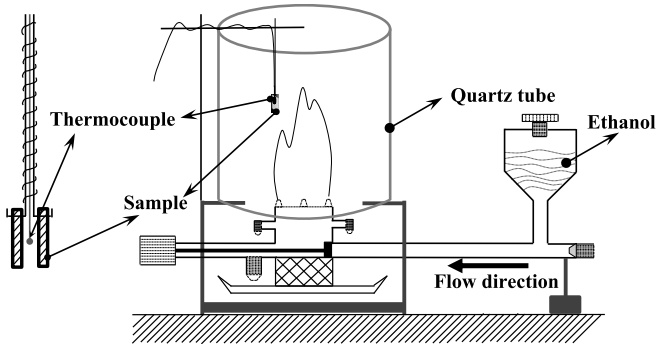

Fig. 1 The device that simulated ethanol-combustion atmosphere.

Table 1 Chemical composition of carbon steel (wt., \%).

\begin{tabular}{lccccc}
\hline C & Mn & Si & S & P & Fe \\
\hline 0.15 & 0.30 & 0.30 & 0.045 & 0.045 & Bal.
\end{tabular}

Bal. = balance; the elements are iron except the other elements.

the metal oxide layer. Therefore, it is important to investigate arson and to clarify the relationship between the type of liquid accelerant, combustion duration and the oxidation behavior of metallic surfaces, to provide information to guide for fire investigation [13-15]. Carbon steel and ethanol are widely used in many aspects of our daily lives. In this study, a laboratory device simulated ethanolcombustion atmosphere was established and hightemperature oxidation properties of carbon steel were investigated.

\section{EXPERIMENTS}

Vaporizing ethanol was used to create a laboratory simulated ethanol-combustion atmosphere. The schematic diagram of the device is shown in Fig. 1. The temperature curve for the combustion process was developed by a K-type thermocouple. The material used in this research is carbon structural steel which is widely used in many aspects of our lives, and its nominal chemical composition is provided in Table 1. Carbon steel ingot was precisionmachined into $3 \times 10 \times 20 \mathrm{~mm}$ sections which were cut using electrical discharge machining (WEDM). A hole with $2 \mathrm{~mm}$ diameter was cut by WEDM at one end to hang the sample, and then ground with 2000 grit $\mathrm{SiC}$ sand paper. The samples were subsequently cleaned in an ultrasonic bath of acetone, rinsed with ethanol and distilled water. It was dried, weighed and their sizes were measured. Finally, the samples were put in the drying oven and spared. The positioning of the sample and thermocouple during the oxidation test is shown in Fig. 1 . The
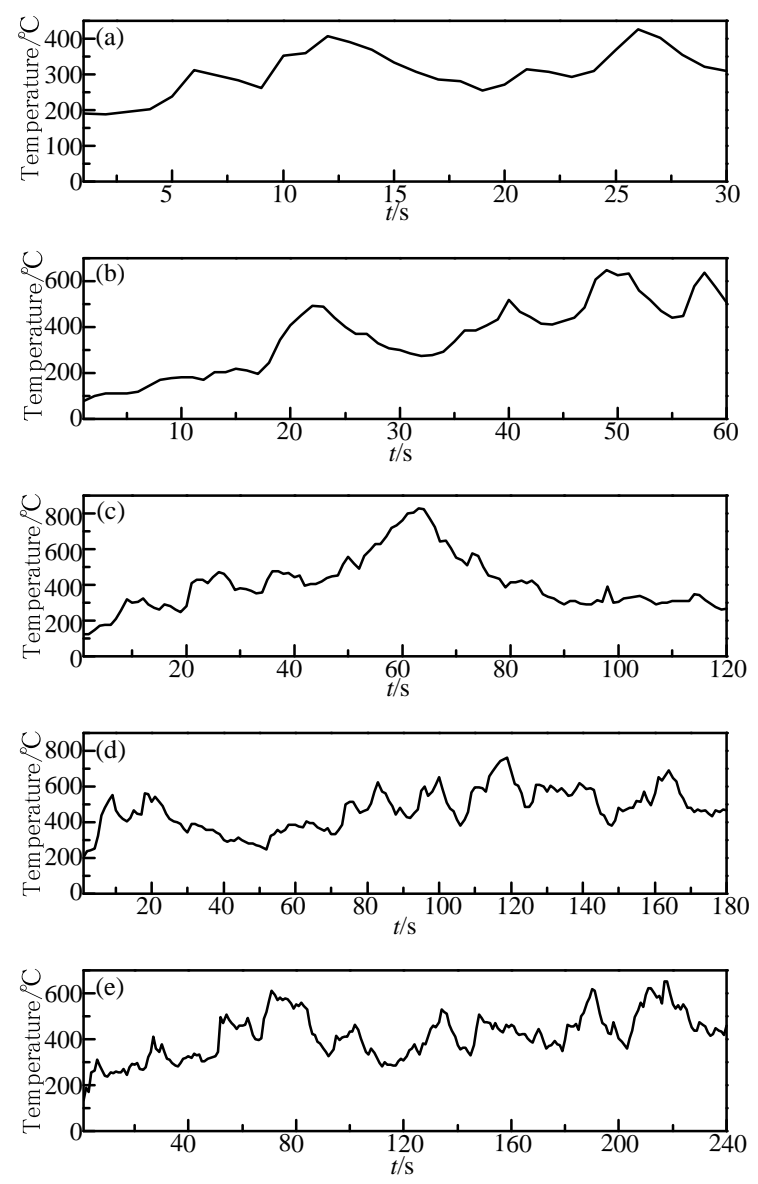

Fig. 2 Temperature curve of oxidation time at (a) $0.5 \mathrm{~min}$, (b) $1 \mathrm{~min}$, (c) $2 \mathrm{~min}$, (d) $3 \mathrm{~min}$ and (e) $4 \mathrm{~min}$.

experimental duration was $0.5,1,2,3$, and $4 \mathrm{~min}$, and the temperature curve is provided in Fig. 2.

After oxidation, the surface morphology and microstructure of the carbon steel were examined with a scanning electron microscope (Leo 1530 FEG SEM, Carl Zeiss SMT Ltd) at an accelerating voltage of $20 \mathrm{kV}$ and scanning probe microscope (CSPM5500, Being Nano-Instruments Ltd). The phase composition of the oxide layer was analyzed using energy dispersive X-ray spectrometer (INCA EDS, Oxford Instruments) and X-ray diffractometer (XRD-6100, Shimadzu).

\section{RESULTS AND DISCUSSION}

Carbon steel undergoes different levels of oxidation when exposed to laboratory simulated ethanolcombustion atmosphere for different durations. In the study, the color of the samples changed during the oxidation process (Fig. 3), probably due to formation of different oxides on the samples [16]. 


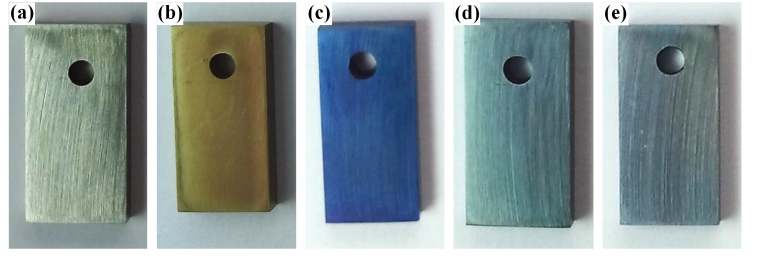

Fig. 3 Visual analyses of the samples after exposure to ethanol containing gas at (a) $0.5 \mathrm{~min}$, (b) $1 \mathrm{~min}$, (c) $2 \mathrm{~min}$, (d) $3 \mathrm{~min}$, and (e) $4 \mathrm{~min}$.

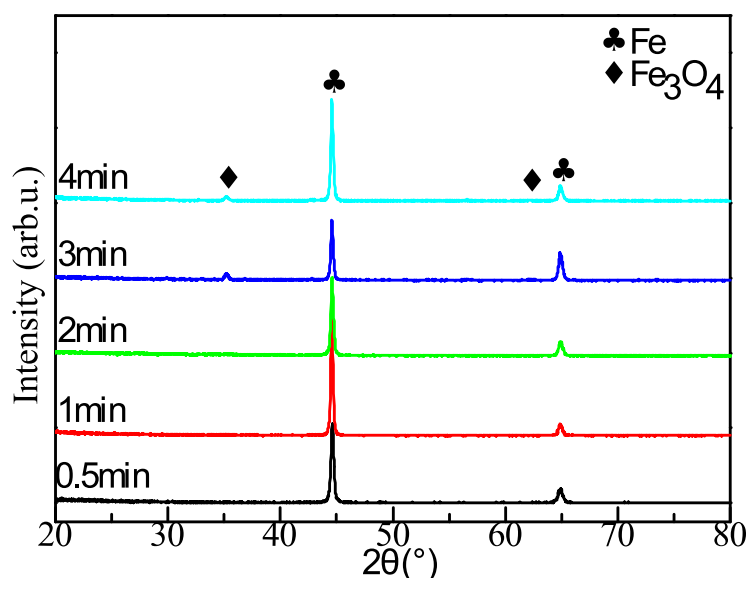

Fig. 4 X-ray diffraction results of carbon steel at ethanol oxidation atmosphere.

The color of the sample surface (Fig. 3de) did not significantly change when the oxidation time exceeded $3 \mathrm{~min}$, indicating that the level of oxidation gradually becomes stable. This phenomenon varies with oxidation time and chemical composition of the surface oxide. During the oxidation process, carbon
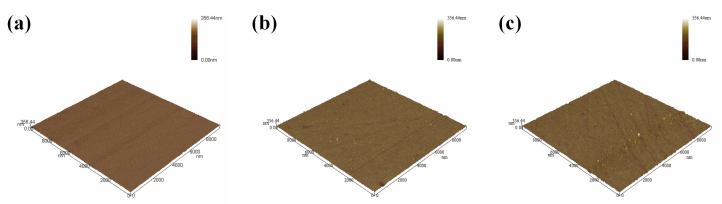

(d)
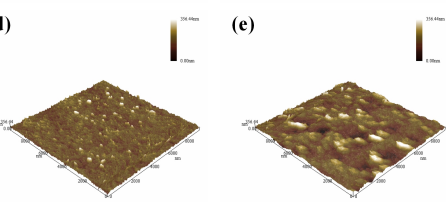

(f)

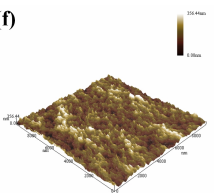

Fig. 5 Scanning probe microscope analysis of the samples after oxidation at (a) $0 \mathrm{~min}$ (unoxidized), (b) $0.5 \mathrm{~min}$, (c) $1 \mathrm{~min}$, (d) $2 \mathrm{~min}$, (e) $3 \mathrm{~min}$, and (f) $4 \mathrm{~min}$.
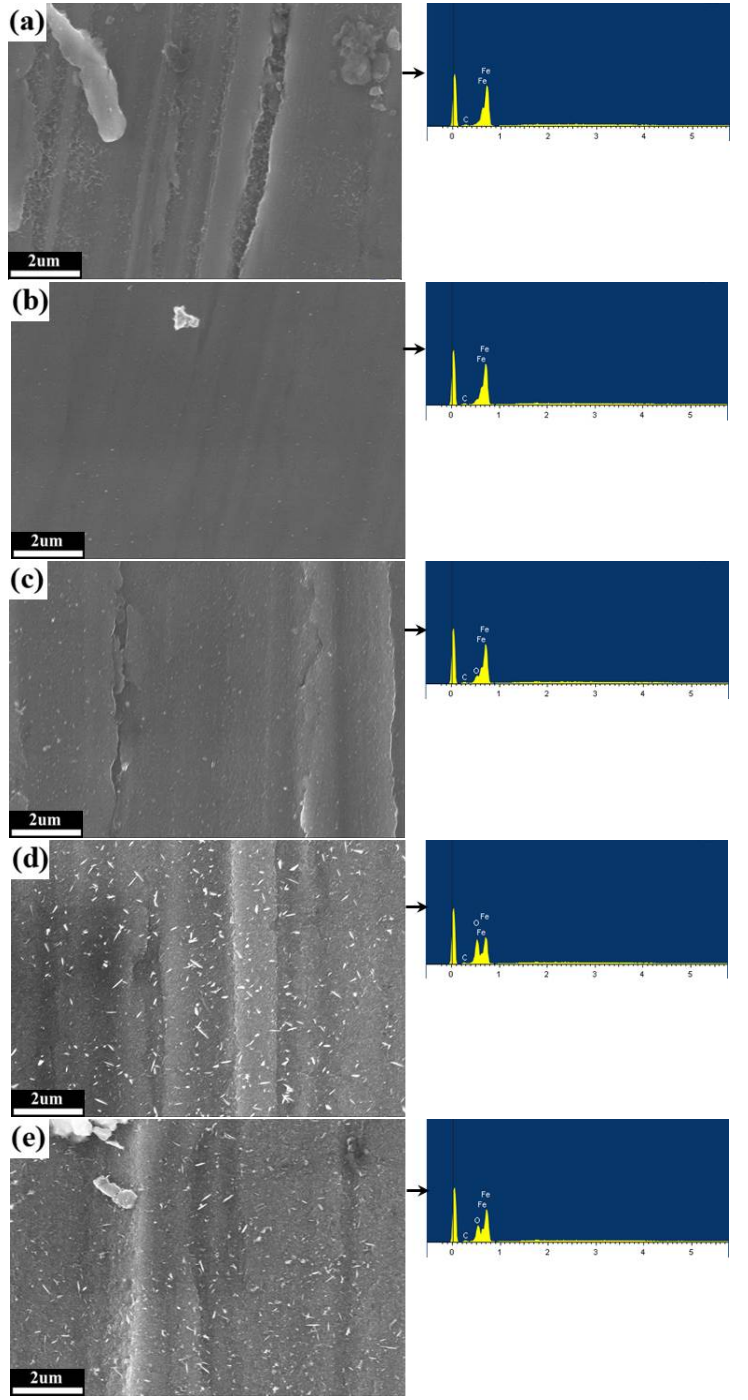

Fig. 6 SEM surface morphology of the samples after oxidation at (a) $0.5 \mathrm{~min}$, (b) $1 \mathrm{~min}$, (c) $2 \mathrm{~min}$, (d) $3 \mathrm{~min}$, and (e) $4 \mathrm{~min}$.

steel materials will form three main components of iron oxide, namely, wustite ( $\mathrm{FeO})$, magnetite $\left(\mathrm{Fe}_{3} \mathrm{O}_{4}\right)$ and hematite $\left(\mathrm{Fe}_{2} \mathrm{O}_{3}\right)$, with different colors [16]. Interestingly, oxidation in the presence of water vapor also produces a variety of $\mathrm{FeXOY} \cdot \mathrm{zH}_{2} \mathrm{O}$ compounds, with varying colors. Visual analysis shows that the color pattern of the alloy after exposure to high temperature depends on the oxides of Fe. The contents of oxides formed under different oxidation stages display different colors on the sample surface along the oxidation process. The presence of polishing marks on the metal surface is due to a thin oxide film [13]. The X-ray diffraction analysis showed that magnetite $\left(\mathrm{Fe}_{3} \mathrm{O}_{4}\right)$ oxides were 
formed on the sample surface when the oxidation duration exceeded 3 min (Fig. 4). In general, the oxide layer formed on carbon steel was oxidized at high temperatures consisted of wustite, magnetite, and hematite. In fact, the high mobility of defects in wustite (FeO) renders this layer to be thicker compared with the magnetite and hematite layers [17]. However, wustite oxides were not found in this study, which may be ascribed to the rapid oxidation caused by strong oxidizing agents present in the ethanol-combustion atmosphere. Interestingly, analysis of the mass changes of samples by thermogravimetric analysis showed a significant weight loss probably caused by the rapid shedding of the oxide layer by the flow of air during the combustion process. The scanning probe microscope revealed that exposure to oxidation for less than $1 \mathrm{~min}$ did not cause significant oxidation on the metal surface compared to the unoxidized state. Notably, only few spot-like white oxides were detected on the sample surfaces (Fig. 5bc). There was a correlation between the different oxides formed on the samples surface and the change in color of samples (Fig. 3). A scanning electron microscope revealed that there was no significant oxidation on the metal surface when the oxidation duration was less than 2 min (Fig. 6abc). But a small amount of white spot oxide particles was observed, which is in good agreement with results of the scanning probe microscope. The amount of white oxide formed on the metal surface is increased with the retention time. Moreover, needle-like oxides were formed on the sample surface when the oxidation duration was more than 3 min (Fig. 6de), and the oxide did not completely cover the sample surface, as revealed by SEM analysis. The mapping results of the EDS shown in Fig. 6 demonstrate that elemental carbon was deposited on the sample surface, which could be due to incomplete combustion of the accelerants. This observation can be used to determine the presence of a combustion accelerant in a fire scene.

During oxidation, a mesh-like pattern was formed on the sample surface, and this pattern was enlarged at the surface defect of the samples when the oxidation duration was 2 min (Fig. 7a). The sample surface was covered by a mesh-like oxide when the oxidation time was extended to 5 min as shown in Fig. 7d. Fig. 7bc show that oxidation is initiated at the defect site on the sample surface, leading to more intense oxidation around it. Notably, the oxidized mesh-like pattern expands outward from the defect. It is related to the large surface energy of defects, which leads to preferential

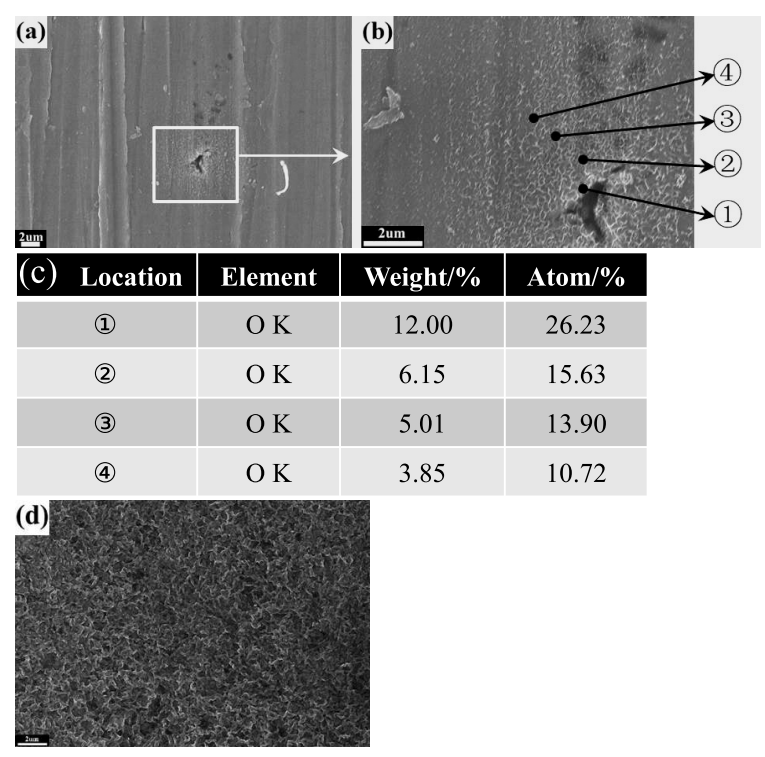

Fig. 7 The SEM and EDS result of samples exposed in laboratory simulated ethanol-combustion atmosphere for $2 \min (\mathrm{a}, \mathrm{b})$ and $5 \min (\mathrm{d})$.

oxidation. The mesh-like pattern may be caused by the grain boundary of the samples.

The oxidation of carbon steel in a laboratory simulated ethanol-combustion atmosphere is characterized by oxidation accompanied with the deposition of carbon and with the formation of a meshlike pattern of oxides on the sample surface. In oxygen-deficient environments, ethanol often undergoes incomplete combustion and pyrolysis according to equations (1)-(6) [18-21], which produces $\mathrm{H}_{2} \mathrm{O}, \mathrm{CO}_{2}$, $\mathrm{CO}$, and $\mathrm{C}$.

$$
\begin{aligned}
\mathrm{CH}_{3} \mathrm{CH}_{2} \mathrm{OH} & \longrightarrow \mathrm{CH}_{2}=\mathrm{CH}_{2}+\mathrm{H}_{2} \mathrm{O} \\
\mathrm{O}_{2}+\mathrm{h} v & \longrightarrow 2 \mathrm{O}^{\circ} \\
\mathrm{CH}_{2}=\mathrm{CH}_{2} & \longrightarrow 2 \mathrm{C}+2 \mathrm{H}_{2} \\
\mathrm{H}_{2}+\mathrm{O}^{\circ} & \longrightarrow \mathrm{H}_{2} \mathrm{O}+\mathrm{h} v \\
\mathrm{C}+\mathrm{O}^{\circ} & \longrightarrow \mathrm{CO}+\mathrm{h} v \\
2 \mathrm{CO}+\mathrm{O}_{2} & \longrightarrow 2 \mathrm{CO}_{2}
\end{aligned}
$$

The EDS results (Fig. 6) indicated that carbon was formed on the sample surface, which is ascribed to the pyrolysis of ethanol. Reactions shown in (4) and (5) would compete with each other under oxygen deficiency conditions. The $\Delta \mathrm{G}^{\circ}$-T plot shows that $\mathrm{H}_{2}$ is preferentially reactive at temperatures below $630^{\circ} \mathrm{C}$ [22]. However, in this study, the temperature range is small, therefore, it can be determined thermodynamically, that elemental carbon deposition occurs during incomplete combustion. 
Chain reactions in the combustion process proceed at a high rate, and $\mathrm{H}_{2}$ is produced as an intermediate product. $\mathrm{H}_{2}$ reacts with oxygen to form water thereby accelerating metal oxidation, or dissolves in oxides to form $\mathrm{H}$ (ox) which enhances ion diffusion and accelerates the formation of oxide layer [23]. The final result is accelerated oxidation of the metal and porous oxide layer [24].

The combustion products, $\mathrm{H}_{2} \mathrm{O}$ and $\mathrm{CO}_{2}$ create a highly oxidizing atmosphere enhancing the oxidation of carbon steel [25-27]. The initial step is the adsorption of the active gas to the metal surface followed by oxide nucleation and growth. The reactions (7) and (8) may occur depending on the atmospheric conditions $[28,29]$.

$$
\begin{aligned}
\mathrm{Fe}+\mathrm{O}_{2} & \longrightarrow \mathrm{FeO} \\
\mathrm{Fe}+\mathrm{CO}_{2} & \longrightarrow \mathrm{FeO}+\mathrm{CO}
\end{aligned}
$$

The $\mathrm{H}_{2} \mathrm{O}_{(\mathrm{g})}$ generated during combustion undergoes cathodic depolarization with $\mathrm{Fe}$ to form $\mathrm{FeOOH}$ at high temperature [28]. The $\mathrm{Fe}^{2+}$ produced from the reaction activates anhydrous ethanol pyrolysis of carbon nanotubes [30-32]. On the other hand, the $\mathrm{H}_{2} \mathrm{O}_{(\mathrm{g})}$ produced during combustion inhibits the dehydration reaction of $\mathrm{FeOOH}$, causing it to react with $\mathrm{Fe}^{2+}$ forming magnetite $\left(\mathrm{Fe}_{3} \mathrm{O}_{4}\right)$, as indicated by the XRD results (Fig. 4).

Elemental carbon was observed on the sample surface, which could be due to incomplete combustion of ethanol, equation (3). The carbon formed during combustion is composed of multilayered graphite molecules [33]. Several studies have shown that $\mathrm{Fe}^{2+}$ has a specific catalytic effect on the thermal decomposition of anhydrous ethanol which leads to the formation of carbon nanotubes when the temperature exceeds $600^{\circ} \mathrm{C}$ [26]. The carbon molecules formed on samples surface can be cleaned by ultrasonication with ethanol, which may be the paragenesis of oxide and carbon. This is different from the soot on the metal surface formed during combustion. Further research is needed to explore this concept.

\section{CONCLUSION}

Cases of arson have received widespread attention in recent years. In this study, the oxidation behavior of carbon steel metal surface was used for fire investigation. The high-temperature oxidation behavior of carbon steel was studied at different duration in a laboratory simulated ethanol-combustion atmosphere. The morphology, microstructure and composition of metal oxides were comprehensively analyzed, as well as the correlation with the oxidation characteristics at different exposure conditions. The laboratory results showed that mesh-like patterns were formed on the surface of carbon steel, which began from the defect sites on the surface of substrate. Due to oxidation in the laboratory simulated ethanol-combustion atmosphere, the pyrolysis of ethanol deposited elemental carbon molecules on the surface of carbon steel. These findings offer valuable information for investigating the causes of fire, as well as determine whether combustion accelerants are present at fire scenes to provide evidence for court cases related to arson.

Acknowledgements: The authors are grateful for the support from the Key Laboratory of Impression Evidence Examination and Identification Technology, Ministry of Public Security, China (2018121705) and Open-fund Project of Jiangxi Key Laboratory of Materials Surface Engineering (KFGJ19009).

\section{REFERENCES}

1. Lentini JJ (2006) Scientific Protocols for Fire Investigation, CRC Press, Florida.

2. Stauffer E, Byron D (2007) Alternative fuels in fire debris analysis: biodiesel basics. J Forensic Sci 52, 371-379.

3. Barbara F, Marta FG, Carlos MA, Danica K, Štefan G, Miguel P, Carmelo GB (2018) Effects of fire suppression agents and weathering in the analysis of fire debris by HS-MS eNose. Sensors 18, ID 1933.

4. Henneberg ML, Morling NR (2018) Unconfirmed accelerants: controversial evidence in fire investigations. Int J Evidence Proof 22, 45-67.

5. keto PO, Wineman PL (1991) Detection of petroleum-based accelerants in fire debris by target compound gas chromatography/mass spectrometry. Anal Chem 63, 1964-1971.

6. Ueta I, Saito Y, Teraoka K, Matsuura H, Fujimura K, Jinno K (2010) Novel fire investigation technique using needle extraction in gas chromatography. Anal Sci 26, 1127-1132.

7. ASTM International (2001) E1386-00 Standard Practice for Separation and Concentration of Ignitable Liquid Residues from Fire Debris by Solvent Extraction, ASTM International, West Conshohocken.

8. ASTM International (2001) E1412-00 Standard Practice for Separation of Ignitable Liquid Residues from Fire Debris Samples by Passive Headspace Concentration with Activated Charcoal, ASTM International, West Conshohocken.

9. ASTM International (2002) E1618-01 Standard Test Method for Ignitable Liquid Residues in Extracts from Fire Debris Samples by Gas ChromatographyMass Spectrometry, ASTM International, West Conshohocken. 
10. Dhabbah AM, Al-Jabe SS, Al-Ghamdi AH, Aqel A (2014) Determination of gasoline residues on carpets by SPME-GC-MS technique. Arab J Sci Eng 39, 6749-6756.

11. Huang Y, Yang V (2009) Dynamics and stability of lean-premixed swirlstabilized combustion. Prog Energy Combust Sci 35, 293-364.

12. NFPA (2008) Guide for Fire and Explosion Investigations, National Fire Protection Association, Massachusetts.

13. Xie DB, Wang W, Lv SL (2018) Effect of simulated combustion atmospheres on oxidation and microstructure evolution of aluminum alloy 5052. Fire Mater 42, 278-285.

14. Boniardi M, Casaroli A (2015) In-depth approach to fire investigations: microstructural analysis of metallic materials. Fire Mater 39, 600-618.

15. Xie DB, Shan G, Deng S, Liu Y (2017) Investigations on oxidation and microstructure evolution of pure $\mathrm{Cu}$ in simulated air-kerosene combustion atmospheres. Fire Mater 41, 614-624.

16. Liu XF, Sun B, Wang JM, Cao GZ (2018) Research progress of high temperature iron oxide scale of steel and iron material during hot rolling. Hot Work Technol 47, 10-19. [in Chinese]

17. Neil B, Gerald HM, Frederick SP (2006) Introduction to the High Temperature Oxidation of Metals, Cambridge University Press, New York.

18. Gao ZC, Wang ZY (2003) The mechanism of alcohol combustion reaction. J Liaoning Univ (Nat Sci) 30, 63-66. [in Chinese]

19. Li J, Kazakov A, Dryer FL (2004) Experimental and numerical studies of ethanol decomposition reactions. J Phys Chem A 108, 7671-7680.

20. Marinov NM (1999) A detailed chemical kinetic model for high temperature ethanol oxidation. Int $J$ Chem Kinet 31, 183-220.

21. Saxena P, Williams FA (2007) Numerical and experimental studies of ethanol flames. Proc Combust Inst 31, 1149-1156.
22. Wang B, Yang B, Song XX (1999) Heat treatment atmosphere. Heat Treat Technol Equip 2, 35-38. [in Chinese]

23. Xu TM, Hui SE (2016) Combustion Science, China Machine Press, Beijing.

24. Fujii CT, Meussner RA (1964) The mechanism of the high-temperature oxidation of iron-chromium alloys in water vapor. $J$ Electrochem Soc 111, 1215-1221.

25. Xie DB, Wtkur W, Wang Z, Li DW, Zang TQ (2017) Effect of combustion adjuvants in fire scene environments on high temperature corrosion of carbon steel. Corros Sci Prot Technol 29, 15-20. [in Chinese]

26. Yun JY, Ha SA, Kang CY, Wang JP (2013) Oxidation behavior of low carbon steel at elevated temperature in oxygen and water vapor. Steel Res Int 84, 1252-1257.

27. Abuluwefa HT, Guthrie RIL, Ajersch F (1997) Oxidation of low carbon steel in multicomponent gases: part I. reaction mechanisms during isothermal oxidation. Metall Mater Trans A 28, 1633-1641.

28. Li J, Su H, Chai F, Chen XP, Li XY, Meng HM (2015) Simulated corrosion test of Q235 steel in diatomite soil. J Iron Steel Res Int 22, 352-360.

29. Xie DB, Shan G, Lv SL (2018) Oxidation behavior of carbon steel in simulated kerosene combustion atmosphere: a valuable tool for fire investigations. Fire Mater 42, 156-163.

30. Zhu HB, Li ZH, Liu ZY, Wang FF, Wang XQ, Wang M (2004) Synthesis of carbon nanotubes by decomposing alcohol. Acta Phys-Chim Sin 20, 191-193.

31. Pan CX, Liu YL, Cao F, Wang JB, Ren YY (2004) Synthesis and growth mechanism of carbon nanotubes and nanofibers from ethanol flames. Micron 35, 461-468.

32. Pan CX, Xu XR (2002) Synthesis of carbon nanotubes from ethanol flame. J Mater Sci Lett 21, 1207-1209.

33. Hao RR, Fan XY, Niu SC (2011) Inorganic Chemistry Series III, China Science Publishing \& Media Ltd, Beijing. 